Dept. of Veterinary Medicine,

College of Agr. and Vet. Med., Saudi Arabia,

Head of Dept. Prof. Dr. E.M. Haroun.

\title{
AN OUTBREAK OF THEILERIA ANNULATA INFECTIONS AMONG FRESIAN CATTLE AT AL GASSIM AREA OF SAUDI ARABIA (With 6 Figures)
}

By

M. MAGZOUB; O.H. OMER; E.M. HAROUN and A.A. MOTTELIB

(Received at $25 / 7 / 1992$ )

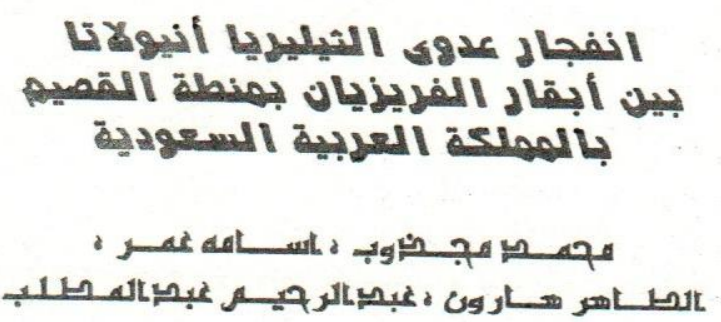

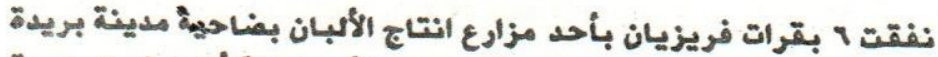

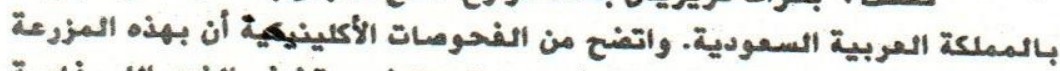

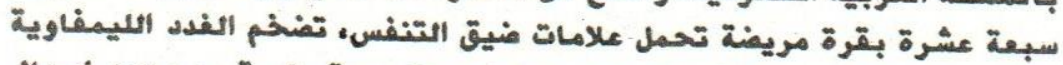

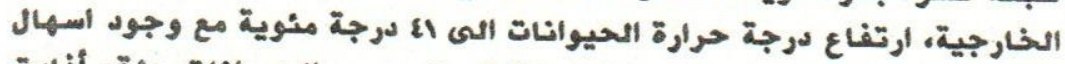

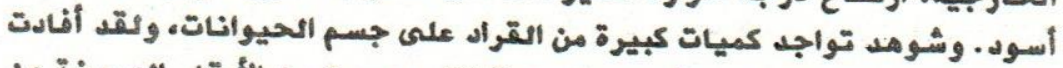

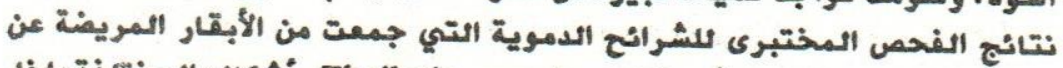

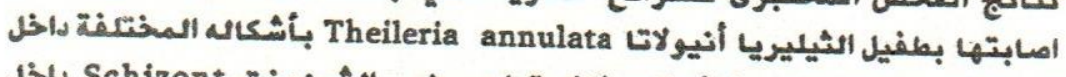

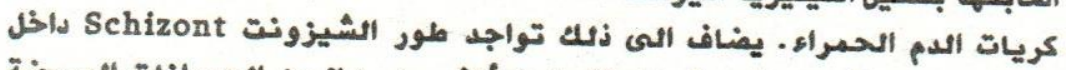

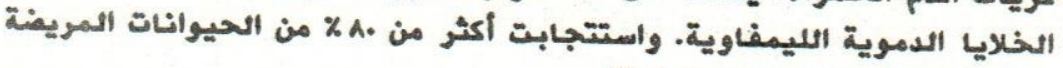

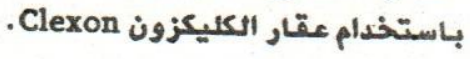

*Dept. of Vet. Med., College of Agric. and Vet. Med., King Saud Univ., Burriedah, P.O. Box 1482. 


\section{SUMMARY}

Six fatality cases out of twenty three infected fresian cattle, in a dairy farm in an outskirt of Burreidah city, were reported to the Department of Veterinary Medicine, College of Agriculture and Veterinary Medicine, King Saud University. Field observations showed clinical signs suggestive of acute Theileria infection marked by fever, reaching up to $41 \mathrm{C}$, respiratory distresses, swellings of the superficial lymph nodes and a black diarrhoea. Almost all the animals were heavily infested with ticks. Mature and immature specimens were quite numerous specially on the ear regions of cattle. They were identified as Hyalomma anatolicum anatolicum. Quick diagnosis was made by the demonstration of schizonts and erythrocytic forms of Theileria annulata in both Leishman and Giemsa stained blood smears. The erythrocytic forms were rodlike, oval, comma-shaped and crescent-shaped. The rate of appearance of these forms was $30 \%$. Schizonts were irregular in shape and quite numerous in the lymphocytes of the circulating blood. Fourteen out of seventeen clinical cases were treated with Clexon drug and showed complete recovery.

\section{INTRODUCTION}

Theileria annulata (Ankara) is readily transmissible by blood passage, and schizonta are fairly numerous in the circulating blood (RISTIC, 1955).

The developmental cycle of Theilera annulata in ticks has been carried out by SCHEIN et al. (1977). The tick vectors of $\underline{T}$. annulata were all members of the genus Halomma; the species in Central Asia and the Middle East as mentioned by RIEK (1966) and SCHEIN (1975) were Hyalomma dromedarii, Hyalomma turanicum, Hyalomma savigny (syn with $\mathrm{H}$. marginatum), $\mathrm{H}$. anatolicum and Hyalomma anatolicum excavatum. KHALIFA (1983 AND 1987) and DIAB (1987) in their reports on ticks of livestock and domestic animals in all regions of Saudi Arabia, determined the occurrence of Hyalomma species in all areas surveyed. The check-list of ticks infesting farm 
animals in Al-Gassim region put forward by KHALIFA (1983) showed the availability and abundance of Hyalomma anatolicum and $\underline{H}$. anatolicum excavatum which were considered by RIEK (1966) and $\operatorname{SCHEIN}^{-} \overline{(1975) \text { to be }}$ natural vectors for T. annulata in Asia.

Serious incidence of infection of T.anulata in cattle causing multiple brain haemorrhage was reported by BARBONI (1942). TSUR-TCHERNOMERETZ et al. (1960) described two cases of bovine T.annulata infection showing clinical symptoms suggestive of several cutaneous lesions scattered in the fornt parts of the body of cattle.

Chlortetracyclines and oxytetracyclines given throughout the incubation period reduced the clinical reactions by decreasing the degree of parasitaemia as pointed out by SCHEIN and VOIGT (1979). These drugs were found to have little effect once clinical disease in apparent. Menoctone and Halofuginone have been shown to be active against clinical infections with T.annulata (SCHEIN and VOIGT, 1979). Recently the chemotherapeutic efficacy of Buparvaquone has been tested against theileriasis in calves caused by T.annulata. Almost all the infected cases were cured (SHARMA and MISHRA, 1990).

In the present study, T.annulata infection among Fresian cattle in an outskirt of Bureidah city at the Middle Region of Saudi Arabia was investigated and affected animals were treated.

\section{MATERIAL and METHODS}

Blood samples from the ear veins of the diseased cattle were taken. Thin and thick smears were prepared on slides; some were stained with Leishman and others with Geinsa. Both stains were found equality satisfactory.

The clinical symptoms were observed and recorded.

Erythrocytic cells were examined for the different forms and shapes of theileria and the ymphocytes were examined as well for schizonts (Koch's blue bodies).

Ticks in different stages of development were carefully removed with forceps mainly from the ear regions of the affected cattle. They were collected and placed in $10 \%$ potasium hydroxide solution for the digestion of internal and contaminated blood. Clove oil was used for the clearance of these specimens and xylene (D.P.X.) for mounting on slides. Microscopic examination for the purpose of identification of ticks was carried out. 
Clexon drug, containing pamaquine substance as an active ingredient (Butalex, Coopers, Animal Health, Ltd, U.K.) was given in the form of a single intramuscular injection of $20 \mathrm{mg} / \mathrm{kg}$. (1 ml clexon $/ 7.5 \mathrm{~kg}$ body wt. of animal).

Blood smears has been collected after treatment to evaluate the efficiency of the drug used.

\section{RESULTS}

Six fatality cases among Fresian cattle in a dairy farm at an outskirt of Bureidah city were delivered to the Department of Veterinary Medicine, Faculty of Agriculture (Gassim branch of King Saud University). Field observations ahowed clinical signs suggestive of acute heileria infection which included mainly marked fever reaching up to $41 \mathrm{C}$, respiratory distresses, swellings of the superficial lymph nodes and a black diarrhea.

Almost all the animals were heavily infested with ticks. Mature and immature specimens were quite numerous specially on the ear retgions of cattle.

The owner treated the affected animals with oxteracyclines but without success and about six animals, out of a total of twenty three, died shortly after treatment. It appears that the mortality rate reached about $26 \%$. The remainders were in a very bad condition and were suffering seriously from infection.

Quick diagnosis was made by the demonstration of schizonts and erythrocytic forms of T.annulata in both Leishman an Giemsa-stained blood smeas (Fig. 1 \& 2). The erythrocytic forms were rod-like, oval comma-shaped and crescent-shaped. The rod-like ones measured 1.5 microns in length by 0.5 microns in width, the oval measured $1.5 \mathrm{um}$ by $0.5 \mathrm{um}$, the comma-shaped measured $1.5 \mathrm{um}$ by $1 \mathrm{um}$ and the crescent bodies measured 2 um by $0.5 \mathrm{um}$ each. The rate of appearance of these forms of parasites was $30 \%$ in such a way that each red blood cell contained only a single parasite in one form or another.

Scizonts (Koch's blue bodies) were irregular in shape and quite numerous in the lymphocytes of the circulating blood (Fig. 3 \& 4). The smallest schizont measured 14 um by 3 um and the largest measured 12 um by 8 um. 
Fourteen out of seventeen clinical cases were successfully treated with Clexon drug and the three remaining cases died during treatment. The tick vector (Fig. 5 \& 6) was identified as hyalomma anatolicum.

\section{DISCUSSION and CONCLUSION}

The severity of the disease theileriasis in cattle as stated by TSUR TCHERNOMERETZ (1960) does not necessarily correspond to the parasitaemia. An animal may be serioulsy ill when less than 25\% of the blood cells are infected and severe reaction may occur where $45 \%$ of the red blood cells are infected. The disease as described in Fresian cattle in the present report was in the acute stage where $30 \%$ of the red blood cells were infected with theileria parasites. According to clinical signs parasitological findings and vector identification, the species of theileria causing the infection was proved and confirmed to be T.annulata (Ankara).

The disease entity is comparable to East Coast Fever caused by Theileria parava, except that the clinical sings of East Coast Fever show rapid emaciation, occurrence of haemoglobinuria and higher rate of mortality reaching $90 \%$. The disease caused by Theileria mutans is non-fatal and the parasites in erythrocytes are either round or oval and measure about 2 um in diameter and about 2-4 parasites occur in a single cell. Schizonts of both T.parava and T.mutans occur in the lymphocytes of the spleen and lymph nodes; they are mostly round and measure up to $20 \mathrm{um}$ in diameter (SOULSBY, 1965).

T.annulata parasites-as shown in the present study-occurred singly in erythrocytes as rod-like, oval, comma-shaped and crescent shaped bodies; measuring $1.5 \mathrm{um}$ in length for the rod-like, oval and comma shapped and 2 um in length for the crescent bodies. Moreover, the schizonts (koch's blue hodles which were irregular in shape-measured $12 \mathrm{um}$ in length by $8 \mathrm{um}$ in width, and they were found in the lymphocytes of the circulating blood,

The tick vectors of T.annulata as stated by SCHEIN et al. (1977) belong to the genus Hyalomma in Central Asia and Middle East. The vector for T.annulata was identified in the present work as H.anatolicum which is in agreement with the findings of RUBAIRE - AKILKI (1990) who studied the susceptibility of the tick H.anatolicum anatolicum to Theileria annulata
infection. 
In conclusion, outbreaks of acute T-annulata infection in Fresian cattle seem to be scarcely reported. The present report is probably the first one in fresian cattle at Al-Gassim in Saudi Arabia. The drug of choice (Clexon) which has been used for the treatment of T.annulata infection in Fresian cattle at a dose rate of $20 \mathrm{mg} / \mathrm{Kg}$ was found to be more than $80 \%$ effective in curing the present acute cases of theileriasis.

\section{REFERENCES}

Barboni, E. (1942): Multiple brain haemorrhage in cattle with Theileria annulata infection. Nuota Vet., 21, 11-15.

Diab, F.M. (1987): Ticks (Acari: Ixodidae) parasitizing livestock in Northern and Eastern Saudi Arabia. Journal of the College of Science, King Saud University, 2: 273-286.

Khalifa, M.S. (1983): A checklist of ticks infesting local farm animals in Saudi Arabia, I. Ticks of Al-Gassim region. Journal of the College of Science, King Saud University, 14: 335-339.

Khalifa, M.S. (1987): Ticks (Acari: Ixodidae) infesting domestic animals in Western \& Southern Saudi Arabia. Arab Gulf. J. Scient. Res. Agric. Biol. Sci., 2: 301-319.

Riek, R.F. (1966): The development of Babesia spp. and Theileria spp. in tick with special reference to those occurring in cattle. In: Biology of parasites; 5 th ed. New York Academic.

Ristic, M. (1966): The vetebrate developmental cyle of Babesia and Theileria. In: Biology of Parasites, 5th, ed. New York. Academic press.

Rubaire - Akilki, C.M. (1990): The effect of bovine tick resistance on the susceptibility of Hyalomma annulata (Ankara). Veterinary Parasitology, 34: 263-288.

Soulsby, E.J.L. (1965): Helminths, Arthropods and Protozoa of Domesticated Animals 5th Ed. New York, Academic Press.

Schein, E. (1975): On the life cycle of Theileria annulata in the mid-gut and haemolymph of Hyalomma anatolicum excavatum. Z. Parasitenk., 47: 165-167.

Schein, E.; Machilborn, H. and Warnecke, M. (1977): Zur Feinstruktur der eryhrocytaren scadien von Theileria annulata (Dechunkowsky, Lubs, 1904). Trop. Med. Parasit., 28: 349-360.

Schein, E. and Voigt, W.P. (1979): Chemotherapy of bovine theileriasis with Halofuginone. Acta Trop., 36: 391-394.

Assiut Vet. Med.J. Vol. 28. No. 55, October 1992. 
Sharma, N.N. and Mishra, A.K. (1990): Treatment of bovine tropical theileriasis with buparvaquone. Trop. Anim. Hlth Prod. 22: 63-65.

Tsur - Tchernomeretz, L.; Davidson, M. and Weissenburg, L. (1960): Two cases of bovine theileriasis (T.annulata), with cutaneous lesions. Refuah. Vet. 17:

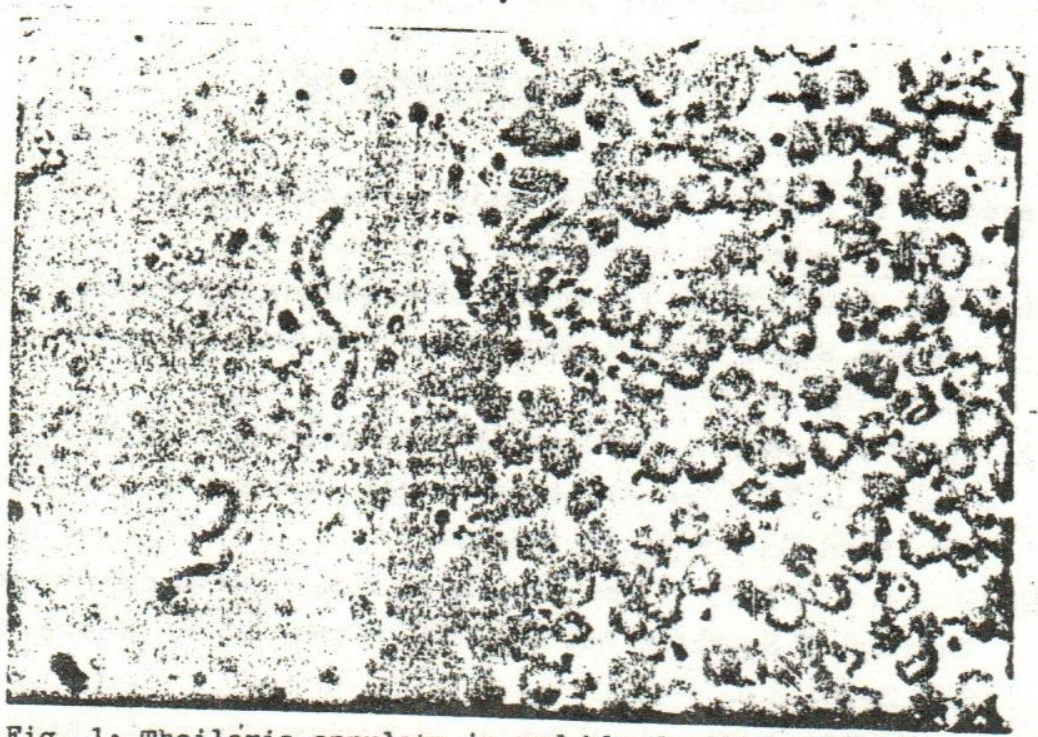

Fig. 1: Theiléria annulata in red blood cells stained

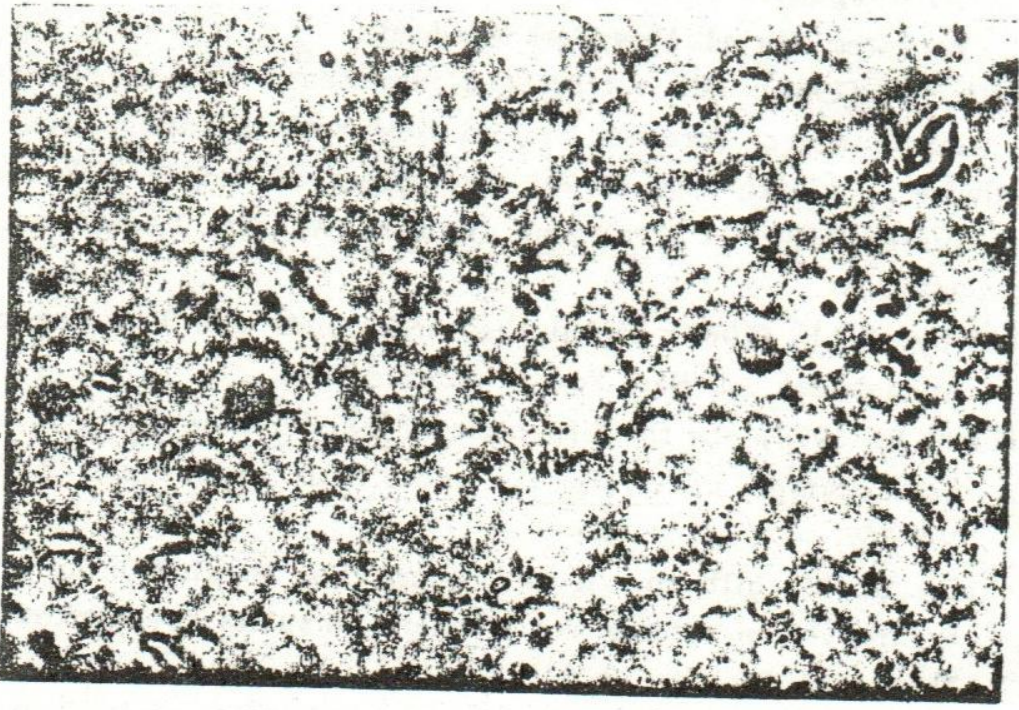

Fig. 2: Theileria annulata in red blood cells stained 


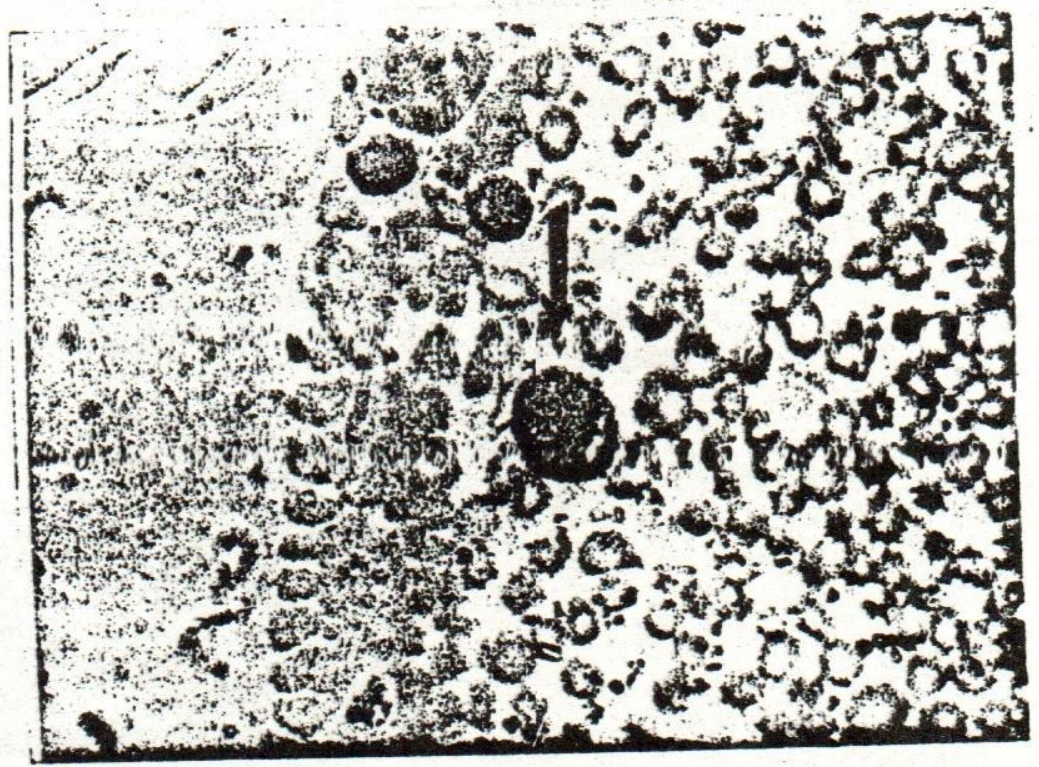

Fig. 3: Koch's blue body in a lymphocyte in blood smear (X 1000). Leishman stain

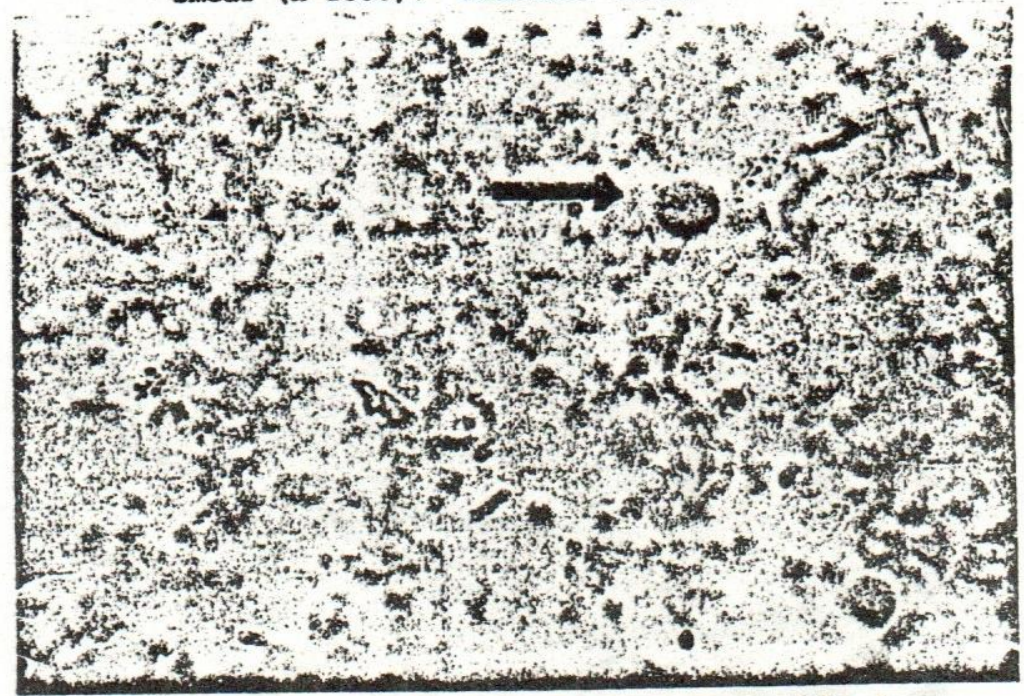

Fig. 4: Koch's blue body in a lymphocyte in blood smear (X 1000). Giemsa stain 


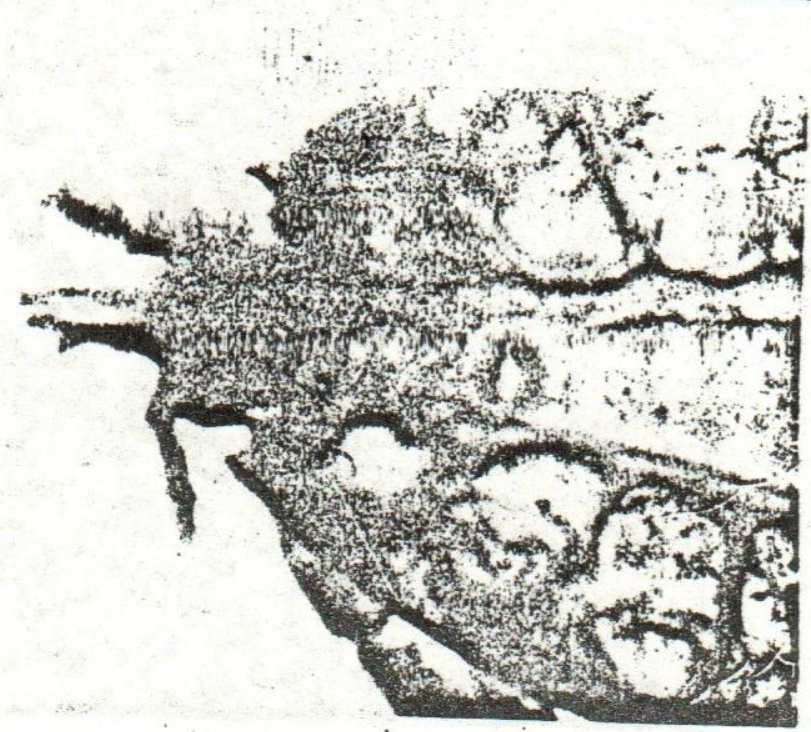

Fig. 5: Ventral view of the anterior end of the male Hyalomma anatolicum anatolicum (x 80$)$.

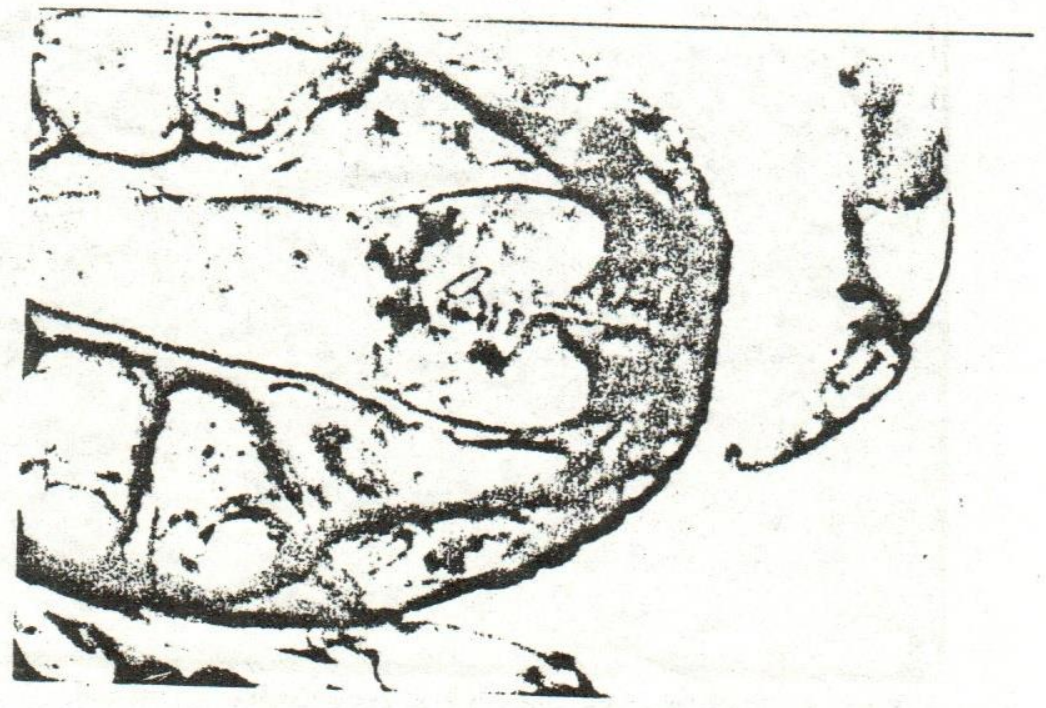

Fig. 6: Ventral view of the posterior end of the male Hyalomma anatolicum anatolicum $(x, 40)$. 